\title{
Urea Nitrogen to Creatinine Ratio Measurement
}

National Cancer Institute

\section{Source}

National Cancer Institute. Urea Nitrogen to Creatinine Ratio Measurement. NCI

Thesaurus. Code C125950.

The determination of the ratio of urea-nitrogen to creatinine present in a sample. The measurement may be expressed as a ratio or percentage. 